EPJ Web of Conferences 110,01072 (2016)

DOI: $10.1051 /$ epjconf/201611001072

(C) Owned by the authors, published by EDP Sciences, 2016

\title{
INFLUENCE OF THE WALL ON THE BOILING REGIME
}

\author{
S. Y. Misyura ${ }^{1, a}$ \\ ${ }^{1}$ Institute of Thermophysics Siberian Branch, Russian Academy of Sciences, Lavrentiev Ave. 1, Novosibirsk, \\ 630090, Russia
}

\begin{abstract}
This work is devoted to investigation of wall roughness and its thickness. It is not enough to know the heat flux and the physical properties of the liquid for determining the boiling mode. The wall roughness and its thickness also plays an important role. Changes in the surface roughness from 5 to 7 th grade did not affect the behavior of the curves. The width of the transition region for the boiling crisis is much less for the polished surface (roughness grade is 9) compared to the rough wall. The boiling crisis for mirror wall comes at a lower overheating of the wall. The total time of evaporation on the mirror wall is almost 3 times higher than for a rough wall.
\end{abstract}

\section{Introduction}

The droplet boiling in heat exchangers can be implemented in various modes depending on the heat fluxes: nucleate boiling; transition crisis (periodic separation of the liquid from the wall); film boiling under the Leidenfrost temperature (boiling crisis). Evaporation of drops was investigated in [1-15]. It is not enough to know the heat flux and the physical properties of the liquid for determining the boiling mode. The wall roughness and its thickness also plays an important role.

Research these factors devoted to this work. This work is devoted to investigation of these factors.

\section{Experimental data}

Experiments were carried out on a horizontal surface under an air atmosphere (temperature of $22{ }^{\circ} \mathrm{C}$ and $1 \mathrm{~atm}$ ). Description of the setup is given in [1]. The wall temperature was maintained constant automatically to within $1{ }^{\circ} \mathrm{C}$. Droplets were obtained using micro dispensers (relative error of less than $2.5 \%$ of volume). Effect of the wall roughness on the process of the distilled water evaporation is shown in Fig. 1. Changes in the surface roughness from 5 to 7 th grade did not affect the behavior of the curves. The width of the transition region for the boiling crisis is much less for the polished surface (roughness grade is 9) compared to the rough wall. The boiling crisis comes at a lower overheating of the wall. The total time of evaporation on the mirror wall is almost 3 times higher than for a rough wall. Changing modes of evaporation for the working section (stainless steel, wall thickness $\delta=1 \mathrm{~mm}$ and the wall temperature $T_{w}=214{ }^{\circ} \mathrm{C}$ ) is shown in Fig. 2. The equivalent droplet diameter was determined from the ratio $V_{0}=4 / 3 \cdot \pi r^{3}$ (where $r$ is the radius of the spherical droplet).

a Corresponding author: misyura@itp.nsc.ru 
When $d<1.5 \mathrm{~mm}$ the droplet detached from the wall and there is a boiling crisis. With an increase in volume $(d=1.5-2 \mathrm{~mm})$, the material does not compensate the intensive cooling and the wall temperature under the droplet is reduced. The lack of separation results in a more intense nucleate boiling (higher heat transfer). When the droplet diameter of about $2 \mathrm{~mm}$ the wall is cooled under the a droplet more stronger and nucleate boiling is stopped, and the evaporation time increases.

Thus, a rough wall surface moves heat exchange crisis towards higher overheating. For thin-walled structures modes of boiling can change. This is important for the calculation of the heat exchangers.

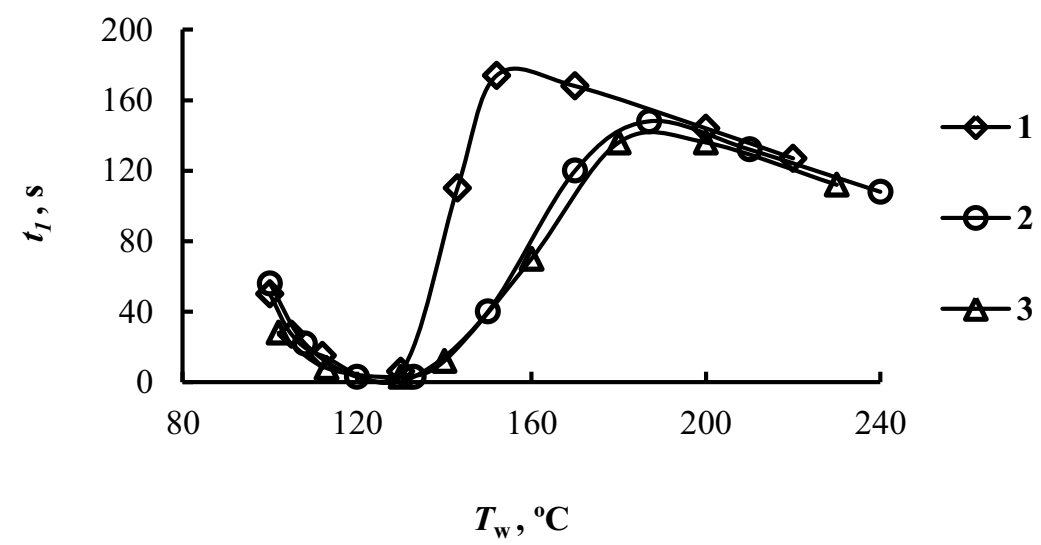

Figure 1. The dependence of the total droplet evaporation time of distilled water on the wall temperature $\left(V_{0}=\right.$ $0.046 \mathrm{~cm}^{3}$, material - copper M1, wall thickness - $30 \mathrm{~mm}$ ): Curve 1 - grade of surface wall roughness is 9 ; Curve 2 - grade is 7; Curve 3 - grade is 5.

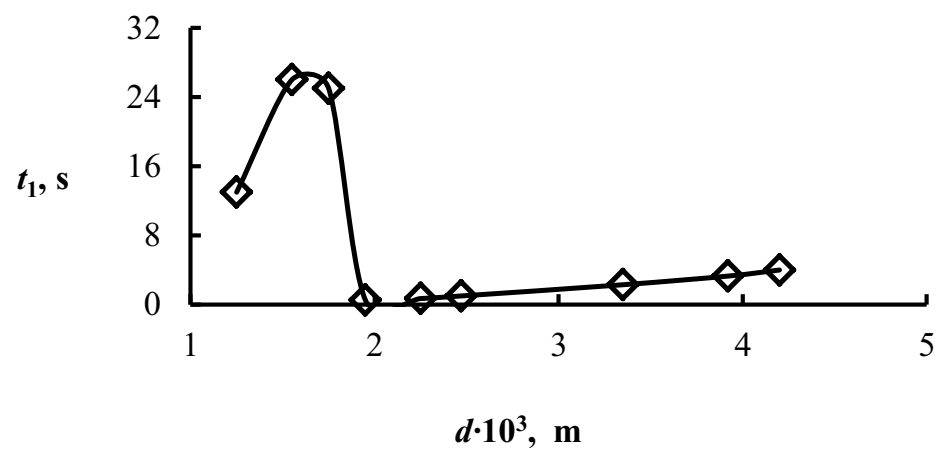

Figure 2. The total time of evaporation depending on the initial droplet diameter (the thickness of wall $(\delta)$ is 1 $\mathrm{mm}$, and $T_{w}=214^{\circ} \mathrm{C}$ ).

\section{Acknowledgements}

This work was supported by grants of Russian Science Foundation (Project № 15-19-10025).

\section{References}

1. V.E. Nakoryakov, S.Y. Misyura, S.L. Elistratov, J. Engineering Thermophysics, 20 (4), 1 (2011)

2. S.Ya. Misyura, Int. J. of Thermal Sci., 92, 34 (2015)

3. B.P. Avksentyuk, V.V. Ovchinnikov, Thermophysics and Aeromechanics, 15, 267 (2008) 
4. D.V. Feoktistov, G.V. Kuznetsov, E.G. Orlova, EPJ Web of Conferences, 76, 012039 (2014)

5. D.V. Feoktistov, K.A. Batischeva, E.G. Orlova, MATEC Web of Conferences, 19, 01001, (2014)

6. M.V. Bartashevich, I.V. Marchuk, O.A. Kabov, Thermophys. and Aeromech., 19 (2), 317 (2012)

7. V.E. Nakoryakov, S.Y. Misyura, Doklady Physics, 59 (10), 441 (2014)

8. V.E. Nakoryakov, S.Y. Misyura, S.L. Elistratov, J. Engineering Thermophysics., 22 (1), 1 (2013)

9. S.Ya. Misyura, Int. J. Heat Mass Transfer, 71, 197 (2014)

10. D.V. Feoktistov, E.G. Orlova, G.V. Kuznetsov, EPJ Web of Conferences, 82, 01053, (2015)

11. D.V. Feoktistov, K.A. Batischeva, E.G. Orlova, EPJ Web of Conferences, 82,01055, (2015)

12. A.N. Pavlenko, E.A. Tairov, V.E. Zhukov, A.A. Levin, M.I. Moiseev, J. Engineering Thermophysics, 23 (3), 173 (2014)

13. V.I. Terekhov, N.E. Shishkin, Technical Physics Letters, 38 (1), 51 (2012)

14. V.E. Nakoryakov, S.Ya. Misyura, S.L. Elistratov, R.A. Dekhtyar, J. Engineering Thermophysics, 23 (4), 257 (2014)

15. S.Y. Misyura, Wall effect on heat transfer crisis, Exp. Thermal Fluid Sci, Doi:http: //dx.doi.org/10.1016/j.expthermflusci.2015.10.002, (2015) 